\title{
Anthropometry Study Using Adult Pelvic 3D CT for Determining Sexes at Dr. Soetomo General Hospital, Indonesia
}

Rosy Setiawati ( $\square$ rosy-s@fk.unair.ac.id )

Airlangga University

Ika Ruriana

Airlangga University

Priyambodo

Airlangga University

Giuseppe Guglielmi

University of Foggia

\section{Research Article}

Keywords: sex identification, anthroprometric study, pelvic 3D CT scan

Posted Date: May 19th, 2021

DOI: https://doi.org/10.21203/rs.3.rs-430082/v2

License: (c) (i) This work is licensed under a Creative Commons Attribution 4.0 International License.

Read Full License 


\section{Abstract}

Pelvic bones are the most reliable indicator of sex in adults because of its sexual dimorphism. Medical imaging modalities e.g. Computed Tomography (CT) provide data sources to examine modern human variation quantitatively. This study aims to determine pelvic anthropometry characteristics and logistic regression formula for adult sex identification obtained from pelvic 3D CT. This study was an observational analytical study with retrospective regression and cross-sectional approach. The population was all patients in Radiology Installation of Dr. Soetomo General Hospital, Surabaya, Indonesia, from September to December 2019 who underwent pelvic 3D CT examination. Then, age distribution and pelvic measurements data were obtained. In this case, statistical analysis was conducted for all the data obtained. A number of 204 samples were included in this study. Mean age of the patients was $50.23 \pm 14.36$ years. All radiologic components were also significantly different between sexes $(p<$ $0.05)$ except for transverse diameter of sacral segment $(p=0.180)$. Moreover, eta test was performed and found that APOD, CPID, LIH, TPO, and SPA had the strongest correlation. Those variables were used for making statistical models with logistic regression as sex $=(0,125 \times \mathrm{CPID})-(0,180 \times \mathrm{LIH})+(0,078 \times \mathrm{SPA})$ $+8,912$. The calculation result $>0$ is a prediction for female while $<0$ is a prediction for male. From logistic regression model calculation, a high validity value (91.05\%) was found with $100 \%$ sensitivity to identify male sex and $81.1 \%$ specificity to identify female sex. There were differences on radiometric variable characteristics in pelvic anthropometric study. The regression formula for sex determination in adults using 3D-CT pelvic provides a pelvic model sex determination with higher validity and sensitivity for male identification, as well as higher a specificity for female identification

\section{Introduction}

Sex identification on remaining human bone is the first step to do in helping forensic anthropologists to identify a person. ${ }^{1}$ The accuracy of sex identification depends on bone components that are analyzed and the technique used. Forensic anthropology is a branch of applied physical anthropology that combines a variety of modified scientific techniques and skills from many scientific disciplines and is used to answer medico-legal related questions. Some of these techniques are quantitative and can be tested empirically e.g. sex and age estimation technique from unidentified bone remains. ${ }^{2,3}$

Conventionally, anthropologists have relied on metric and non-metric observational analyses of actual bones. ${ }^{3}$ Medical imaging modalities e.g. Computed Tomography (CT) provide data sources to examine modern human variation quantitatively when expanding the resources for osteological assessment to researchers. These studies have shown significant improvements in accuracy and reproducibility over conventional linear methods of constructing a person's biological profile. ${ }^{4,5}$

Various attempts have been made to be able to 'metricize' or measure non-metric properties accurately in several body areas. ${ }^{5,6}$ More objective data for sex estimation might allow very accurate results along with metricization of certain non-metric pelvis areas. ${ }^{1}$ Moreover, other pelvic indices such as those used in clinical medicine might be used to supplement and give additional measurements in anthropological 
assessment. In adults, pelvic bones are the most reliable indicator of sex because of its sexual dimorphism. Each population must have a special identification standard. ${ }^{3}$ This study aims to determine pelvic anthropometry characteristics obtained from pelvic 3D CT in identifying adults' sex in Dr. Soetomo General Hospital, Surabaya, Indonesia.

\section{Materials And Methods Study design}

This study was an observational analytical study with retrospective regression and cross-sectional approach. The population was all patients in Radiology Installation of Dr. Soetomo General Hospital, Indonesia, from September to December 2019 who underwent pelvic 3D CT examination. All methods were carried out in accordance with relevant guidelines and regulations

\section{Sample of study}

The sample of this study was pelvic 3D CT data which obtained from consecutive sampling that suited to the inclusion and exclusion criteria. The inclusion criteria were pelvic 3D CT images of Radiology Installation's patients, both male and female patients whose age more than 18 years old and CT scan image of non-pregnant women. On the other hand, the exclusion criteria in this study were pelvic 3D CT images of patient's pelvis and sacrum which reveal a pathological condition that might interfere measurement, chronic disease and osteoporosis.

\section{Ethical clearance}

The study was performed according to the Ethical principles of declarations of Helsinki. This study was approved by Medical Research Ethic Committee of Dr. Soetomo General Hospital, Surabaya for ethical clearance with registration number: 0106/LOF/301.4.2/VIII/2020. All participants included had given their written informed consent to participate in this study.

\section{Study procedure}

Pelvic CT scans examinations in the form of digital data served as study material. Furthermore, radiological examination tool used a 16-slices Siemens SOMATOM CT scan machine in Radiology Installation of Dr. Soetomo Surabaya General Hospital. Demographic data were obtained from medical records.

The age distribution and pelvic measurements data were obtained as well. Pelvic measurements that were obtained in this study are portrayed in Table 1. 
Table 1

Pelvic measurements using 3D-CT Scan

No. Measurement

1. Anterior breadth of the sacrum (ABS)

2. Anterior height of sacrum (AHS)

3. Anteroposterior pelvic outlet diameter (APOD)

4. Conjugate pelvic inlet diameter (CPID)

5. Left iliac breadth (LIB)

6. Left ischium length (LIL)

7. Left pubic length (LPL)

8. Left width of greater sciatic notch (LGSN)

9. Left innominate height (LIH)

10. Pubic symphysis length (PSL)

11. Right ischium length (RIL)

12. Right pubic length (RPL)

13. Right width of greater sciatic notch (RGSN)

14. Right iliac breadth (RIB)

15. Right innominate height $(\mathrm{RIH})$

16. Sub pubic angle (SPA)

17. Transverse diameter of sacral segment 1 (TDSS)

18. Transverse pelvic inlet (TPI)

\section{Definition}

Maximum transverse points of sacrum at anterior projection of auricular surface

Distance between sacral promontory and sacral/coccyx border

Distance between coccyx and inferior pubic symphysis

Distance between sacral promontory and superior pubic symphysis

Distance between anterior superior iliac spine to left superior posterior iliac spine (taken from the left side)

Distance between acetabular junction and the innermost point of ischial tuberosity (taken from the left side)

Distance between a point at acetabular junction and the superior point at pubic symphysis (taken from the left side)

The line between iliac spine, the innermost part of greater sciatic notch, and ischial spine (taken from the left side)

Distance between the most superior point of iliac crest and the lowest point of ischial tuberosity (taken from the left side)

Distance between the most superior and inferior points of pubic symphysis (taken from the left side)

Distance between acetabular junction and the innermost point of ischial tuberosity (taken from the right side)

Distance between a point at acetabular junction and the superior point at pubic symphysis (taken from the right side)

The line between iliac spine, the innermost part of greater sciatic notch, and ischial spine (taken from the right side)

Distance between anterior superior iliac spine to left superior posterior iliac spine (taken from the right side)

Distance between the most superior point of iliac crest and the lowest point of ischial tuberosity (taken from the right side)

Angle between iliac spine, the innermost part of great sciatic notch and ischial spine

Distance between the two most lateral points of the first sacral segment

Distance between coccyx and inferior pubic symphyis 


\begin{tabular}{|lll|}
\hline No. & Measurement & Definition \\
\hline 19. & $\begin{array}{l}\text { Transverse pelvic outlet } \\
\text { (TPO) }\end{array}$ & $\begin{array}{l}\text { Distance between sacral promontory and superior pubic } \\
\text { symphysis }\end{array}$ \\
\hline 20. & Left IschPub Index & Pubic length $(\mathrm{x} 100)$ divided with ishcial length \\
\hline
\end{tabular}

\section{Statistical analysis}

T-test analysis was used when the data was parametric; however, Mann Whitney test was used when the data was non-parametric. The purpose was to determine a significant difference between sexes. The correlation strength analysis was conducted using eta test if there were significant differences. Moreover, the variable with the strongest correlation was tested to find the regression formula to determine an adult's sex. Then, after the formula was determined, the variable was used to test the second observation group. Afterwards, the validity and specificity were measured. Chi square test was conducted to determine correlation relationship. Multivariate calculations were performed using binominal logistic regression on four variables with the highest correlation strength.

\section{Results}

\section{Study sample demography}

There were 204 patients who were included in this study. Most of the samples were male with female-tomale ratio of $1: 1.13$.

Mean age of the patients was $50.23 \pm 14.36$ years and the mean age of male group older than female group. Patient's age was divided according to age group, with an age range of 10 years for each group. Group with the most patients was 41-50 years age group and followed by 51-60 years age group. Most men were included in 51-60 years age group while most female were included in 41-50 years age group (Table 2). 
Table 2

Age group of patients

\begin{tabular}{|llll|}
\hline \multirow{2}{*}{ Age group (years) } & \multicolumn{2}{l}{ Sex } & \multicolumn{2}{c|}{ Total } \\
\cline { 2 - 3 } & Male & Female & \\
\hline $11-20$ & 2 & 3 & 5 \\
\hline $21-30$ & 7 & 10 & 17 \\
\hline $31-40$ & 10 & 11 & 21 \\
\hline $41-50$ & 27 & 32 & 59 \\
\hline $51-60$ & 31 & 16 & 47 \\
\hline $61-70$ & 25 & 21 & 46 \\
\hline $71-80$ & 3 & 1 & 4 \\
\hline $81-90$ & 3 & 2 & 5 \\
\hline
\end{tabular}

\section{Radiologic components}

In this study, radiologic components consist of pelvic measurement results. Pelvic measurement values were taken for the entire sample. Data were presented in the form of mean and standard deviation and further divided by sex. Table 3 provides pelvic measurement results.

Several variables were found to have a greater size for men than women i.e. ABS, AHS, bilateral IB, bilateral IH, RIL, PSL. 
Table 3

Mean and standard deviation of radiologic components

\begin{tabular}{|c|c|c|c|c|c|}
\hline \multirow[t]{2}{*}{ Radiologic components } & \multicolumn{2}{|l|}{ Male } & \multicolumn{2}{|l|}{ Female } & \multirow{2}{*}{$\begin{array}{l}\mathrm{P} \\
\text { Value }\end{array}$} \\
\hline & Mean & $\begin{array}{l}\text { Standard } \\
\text { Deviation }\end{array}$ & Mean & $\begin{array}{l}\text { Standard } \\
\text { Deviation }\end{array}$ & \\
\hline $\begin{array}{l}\text { Anterior breadth of the sacrum } \\
\text { (ABS) }\end{array}$ & 95.89 & 7.90 & 91.98 & 13.44 & $0,004^{\mathrm{a}}$ \\
\hline Anterior height of sacrum (AHS) & 102.86 & 8.99 & 100.25 & 9.00 & $0,034^{b}$ \\
\hline $\begin{array}{l}\text { Anteroposterior pelvic outlet } \\
\text { diameter (APOD) }\end{array}$ & 82.81 & 8.21 & 88.58 & 9.21 & $\begin{array}{l}<, 001^{b} \\
k\end{array}$ \\
\hline $\begin{array}{l}\text { Conjugate pelvic inlet diameter } \\
\text { (CPID) }\end{array}$ & 107.44 & 7.78 & 120.68 & 35.77 & $<0$ \\
\hline Left iliac breadth (LIB) & 116.97 & 9.79 & 113.85 & 11.59 & $\begin{array}{l}< \\
0,001^{a}\end{array}$ \\
\hline Left ischium length (LIL) & 79.05 & 6.03 & 75.10 & 4.61 & $<0$ \\
\hline Left pubic length (LPL) & 66.04 & 6.25 & 66.79 & 4.13 & $0,021^{\mathrm{a}}$ \\
\hline $\begin{array}{l}\text { Left width of greater sciatic notch } \\
\text { (LGSN) }\end{array}$ & 43.89 & 13.63 & 47.84 & 4.97 & $<, 001^{\mathrm{a}}$ \\
\hline Left innominate height $(\mathrm{LIH})$ & 197.53 & 7.91 & 178.66 & 20.03 & $<0$ \\
\hline Pubic symphysis length (PSL) & 29.71 & 3.45 & 28.46 & 3.00 & $0,011^{\mathrm{a}}$ \\
\hline Right ischium length (RIL) & 79.29 & 5.82 & 73.73 & 10.84 & $<0,001^{\mathrm{a}}$ \\
\hline Right pubis length (RPL) & 65.65 & 3.80 & 68.60 & 21.21 & $0,024^{a}$ \\
\hline $\begin{array}{l}\text { R width of greater sciatic notch } \\
\text { (RGSN) }\end{array}$ & 42.84 & 4.19 & 47.16 & 7.00 & $<0$ \\
\hline Right iliac breadth (RIB) & 117.69 & 5.28 & 112.70 & 9.24 & $<0,001^{a}$ \\
\hline Right innominate height (RIH) & 195.96 & 18.81 & 178.96 & 11.54 & $<0$ \\
\hline
\end{tabular}

${ }^{a}$ non-parametric difference test using Mann-Whitney test, ${ }^{b}$ parametric difference test using $\mathrm{t}$-test, ${ }^{*} \mathrm{Not}$ significant 


\begin{tabular}{|c|c|c|c|c|c|}
\hline \multirow[t]{2}{*}{ Radiologic components } & \multicolumn{2}{|l|}{ Male } & \multicolumn{2}{|l|}{ Female } & \multirow{2}{*}{$\begin{array}{l}\mathrm{P} \\
\text { Value }\end{array}$} \\
\hline & Mean & $\begin{array}{l}\text { Standard } \\
\text { Deviation }\end{array}$ & Mean & $\begin{array}{l}\text { Standard } \\
\text { Deviation }\end{array}$ & \\
\hline Sub pubic angle (SPA) & 99.69 & 11.78 & 128.01 & 14.43 & $\begin{array}{l}< \\
0,001^{a}\end{array}$ \\
\hline $\begin{array}{l}\text { Transverse diameter of sacral } \\
\text { segment } 1 \text { (TDSS) }\end{array}$ & 106.87 & 5.21 & 108.20 & 6.81 & $0,180^{b^{*}}$ \\
\hline Transverse pelvic inlet (TPI) & 114.03 & 6.64 & 122.48 & 6.52 & $\begin{array}{l}< \\
0,001^{b}\end{array}$ \\
\hline Transverse pelvic outlet (TPO) & 94.00 & 7.64 & 108.90 & 9.57 & $\begin{array}{l}< \\
0,001^{a}\end{array}$ \\
\hline Left IschPub Index (LIPI) & 84.02 & 11.26 & 89.12 & 5.80 & $\begin{array}{l}< \\
0,001^{a}\end{array}$ \\
\hline
\end{tabular}

Furthermore, the data were divided based on each component of pelvic measurements obtained.

In this study, 19 out of 20 variables had significant differences $(p<0.05)$ between male and female group. One variable that did not have a significant difference between male and female group was transverse variable diameter of sacral segment 1 variable $(p=0.180)$. Variables that have significant differences were analyzed for their correlation strength using eta test. The results of the analysis can be seen in Table 4. 
Table 4

Correlation strength test between variables with eta test

\begin{tabular}{|lll|}
\hline Radiologic component measurement & Eta value & $\mathbf{p}$ \\
\hline Right iliac breadth (RIB) & 0.231 & 0.447 \\
\hline Pubic symphysis length (PSL) & 0.705 & 0.733 \\
\hline Right pubis length (RPL) & 0.751 & 0.529 \\
\hline Left pubic length (LPL) & 0.816 & 0.363 \\
\hline R width of greater sciatic notch & 0.834 & 0.289 \\
\hline Left ischium length (LIL) & 0.838 & 0.290 \\
\hline Left width of greater sciatic notch & 0.847 & 0.428 \\
\hline Right ischium length (RIL) & 0.855 & 0.378 \\
\hline Left iliac breadth (LIB) & 0.857 & 0.239 \\
\hline Transverse pelvic inlet (TPI) & 0.859 & 0.434 \\
\hline Anterior breadth of the sacrum (ABS) & 0.883 & 0.427 \\
\hline Left IschPub Index (LIPI) & 0.893 & 0.331 \\
\hline Anterior height of sacrum (AHS) & 0.899 & 0.428 \\
\hline Right innominate height (RIH) & 0.926 & 0.245 \\
\hline Anteroposterior pelvic outlet diameter (APOD) & 0.955 & 0.154 \\
\hline Conjugate pelvic inlet diameter (CPID) & 0.945 & 0.302 \\
\hline Left innominate height (LIH) & 0.960 & 0.183 \\
\hline Transverse pelvic outlet (TPO) & 0.972 & 0.120 \\
\hline Sub pubic angle (SPA) & 0.982 & 0.204 \\
\hline
\end{tabular}

Eta value above 0.900 considered to be the limit when a variable had the highest effect. In this case, highest correlation between variables was RIH, APOD, CPID, LIH, TPO, and SPA. The innominate height variable had a high correlation strength for both sides (left and right), therefore, the authors decided to take the left side of innominate height $(\mathrm{LIH})$ of pelvis to avoid result duplication and artificial inflation of the calculation results in making statistical models. Variables that used for making statistical models with logistic regression were APOD, CPID, LIH, TPO, and SPA

\section{Making statistical models with logistic regression statistical analysis}


Multivariate calculations were performed using binomial logistic regression on four variables with the highest correlation strength. Logistic regression calculations are presented in Table 5.

Table 5

Logistic regression analysis of APOD, CPID, LIH, SPA and TPO in calibration group

\begin{tabular}{|lllll|}
\hline Variables & $\boldsymbol{\beta}$ & Wald & $\mathbf{p}$ & OR \\
\hline APOD & 0.038 & 0.678 & 0.410 & 1.038 \\
\hline CPID & 0.125 & 4.443 & 0.035 & 1.133 \\
\hline LIH & -0.180 & 16.243 & 0.001 & 0.835 \\
\hline SPA & 0.078 & 5.901 & 0.015 & 1.081 \\
\hline TPO & -0.007 & 4.443 & 0.864 & 0.993 \\
\hline Constant & 8.912 & 0.976 & 0.323 & 7423.517 \\
\hline
\end{tabular}

From Table 6, it can be seen that the variable with a significant value for further use in logistic regression formula model from calibration group were CPID $(p=0.035)$, LIH $(p=0.001)$ and SPA $(p=0.015)$.

Table 6

Omnibus test of logistic regression model coefficients in calibration group

\begin{tabular}{|llll|}
\hline Step 1 & Chi-square & df & $\mathbf{p}$ \\
\hline Step 1 & & & \\
\hline Step & 133.746 & 5 & 0.000 \\
\hline Block & 133.746 & 5 & 0.000 \\
\hline Model & 133.746 & 5 & 0.000 \\
\hline
\end{tabular}

The formula generated by logistic regression model from calibration group was obtained as follows:

Sex $=(0,125 \times$ CPID $)-(0,180 \times$ LIH $)+(0,078 \times$ SPA $)+8,912$

If the result $>0$ the predicted sex is female, whereas, if the result $<0$ the predicted sex is male. A case illustration of using the logistic regression formula in female pelvic parameters is described in Fig. 1.

\section{Logistic regression model validity}

Logistic regression model was applied in the studied groups to determine the formula accuracy. Data of model validity are presented in Table 7. 
Table 7

Logistic regression formula validity in determining sex of the studied groups

\begin{tabular}{|c|c|c|c|c|}
\hline \multirow[t]{2}{*}{ Sex } & \multicolumn{2}{|c|}{ Correct sex } & \multirow[t]{2}{*}{$\mathbf{n}$} & \multirow[t]{2}{*}{ p } \\
\hline & Male & Female & & \\
\hline Sex prediction according to formula & & & & $<0.001$ \\
\hline Male & 40 & 5 & 45 & \\
\hline Female & 0 & 23 & 23 & \\
\hline Total & 40 & 28 & 68 & \\
\hline Sensitivity & $100 \%$ & & & \\
\hline Specificity & $82.1 \%$ & & & \\
\hline Total accuracy & $91.05 \%$ & & & \\
\hline
\end{tabular}

From logistic regression model calculation, a high validity value (91.05\%) was found with $100 \%$ sensitivity to identify male and $81.1 \%$ specificity to identify female.

\section{Discussion}

Sex identification of skeletal remains is an important issue in forensic medicine. ${ }^{2}$ The pelvic bones are the most reliable gender differentiation parameter because it is the most dimorphic bone, especially in adult individuals. ${ }^{2}$ Each population has its special identification standard. ${ }^{2}$ Implementing visual or morphological techniques is the quick way to assess the samples. The weakness of this technique is in the sense of a very subjective assessment which requires an experienced observers and the level of accuracy is still not guaranteed. Moreover, sexual dimorphism varies geographically. Therefore, forensic anthropologists are constantly trying to test the existing methods and developing standards that are more efficient and objective in which it can optimize the positive identification of the human skeleton. ${ }^{7-10}$ The use of advance imaging technology with multislice computed tomography (MSCT) for anthropological purposes is recently developed. It is a suitable tool for determining sexual dimorphic characteristics in various anatomies area. $3,4,6,11$ This study demonstrates the importance of an objective method utilizing radiological technology in human anthropometric determination in order to assist the analysis of sex identification.

The mean age of sample in this study was $50.23 \pm 14.36$ years. Moreover, a study conducted by Kolesova et al, pelvic size difference was associated with changes in age. Age-related changes observed in the study were carried out in linear parameters of pelvic cavity and confirmed the anterior tilt of sacral floor as well as more horizontal sacrum location in accordance to aging. This study also showed that there was no change in pelvic proportion to ischial height in female while the distance of transverse pelvic diameter shortens with age. ${ }^{7}$ As it is stated previously, age-related ankylotic processes decreased sacroiliac joints motility and facilitated these changes. ${ }^{8-10}$ 
There were significant differences $(\mathrm{p}<0.05)$ on radiologic components measured between male and female except for transverse diameter of the sacral segment $(p=0.180)$. These significant differences finding was similar to other studies in different populations which there were significant differences in pelvic measurements between the sexes. ${ }^{9,11}$ In a study by Patriquin et al., they demonstrated significant sexual dysmorphism in a population study on South Africa. This study reported differences in pelvic size between sexes as well as differences between races. ${ }^{9}$

Furthermore, this study shows a significant difference in APOD measurement between male and female group. This result is in accordance to a study conducted by Kolesova and Vetra, that there was significant difference in APOD measurements of the two sexes. ${ }^{12}$ The result obtained from our study provides a lower mean of APOD value than their study, but it is similar in the sense of APOD value for male due to the fact that it has lower mean than female. The measurement of CPID component in this study showed a higher value in female group.

In previous study, male pelvic structure is significantly heavier and thicker than female. The male pelvis is also adjusted to fit in more massive and sturdy body architecture e.g. the male acetabulum has been designed to fit a larger femur. Even though most of pelvic sexual dimorphisms are due to size differences, sex-related shape variations are also very striking and cannot be considered as an allometric differences in body size between both sexes. ${ }^{13}$ This variation in shape is indicated by a rounder frame of female pelvis. Sciatic indentation is wider in female rather than those in male. They have larger, shallower, lower, bigger pelvis and larger pelvic inlet and outlet (Pubic bone is longer and curvature degree of pectineal line is greater). Therefore, women's pelvic bones also differ in characteristics related to sacroiliac joints position on the iliac bones. ${ }^{14}$

The SPA measurement showed a significant difference between male and female group with high correlation strength. This result is in accordance to previous studies which concluded that SPA was the most reliable indicator of pelvic sex. ${ }^{15}$ This is also in accordance to a study by Igbigbi and Msamati, who stated that the accuracy of SPA dimensions in determining sex was $94.7 \%$ for female and $95.5 \%$ for male. ${ }^{16}$ Moreover, a similar result is also portrayed in a study by Mostafa, which showed a significant difference in SPA measurements between both sexes. ${ }^{17}$ Women's growth tend to increase during adolescence, especially in ischium and pubic areas, resulting in a larger pelvic outlet, longer pubic and a blunter SPA. This growth difference is related to sexual dimorphism associated to birth process. ${ }^{18,19}$

The TPO measurement showed a significant difference in both sexes with high strength of correlation between male and female group. These findings are in accordance to previous studies which concluded that a significant difference was observed in transverse diameter of pelvic midplane and outlet. This could be explained by hormonal effects of pregnancy which result in pubic symphysis softening and pubic bone movement as wide as one $\mathrm{cm}$, as a consequence there was an increase on pelvic diameter. ${ }^{12,17}$ 
The APOD, CPID, LIH, SPA, and TPO were conducted through multivariate analysis using logistic regression in order to find significant variables and generate a formula that might determine a person's sex with high accuracy. The CPID, LIH, and SPA components showed significant values in accordance to previous discussion. These three components consistently showed differences in sexual dysmorphism in both sexes, especially SPA served as one of the high scoring factors consistently. This study shows that the estimated values of pelvic measurements using 3D-CT could provide a pelvic model with a formula that has a high accuracy value using CPID, LIH, and SPA values with $p=0.035, p=0.001$ and $p=0.015$ respectively. This formula was able to provide a high overall validity $(91.05 \%)$ with $100 \%$ sensitivity for male identification and $81.1 \%$ specificity for female identification. Nevertheless, these results need to be compared with previous studies in which they were able to provide higher validity values that could reach $100 \% \cdot{ }^{3,17}$

This study has some limitations that it has few data from patients under 30 years of age, therefore multicentric study with more population under 30 years of age is needed to obtain a greater variety of data and produce more accurate formula for sex determination. In addition, an analytical study of previously published studies may be carried out to compare differences the value of pelvic anthropometry of various races and geographic areas.

\section{Conclusion}

There were differences on radiometric variable characteristics in pelvic anthropometric study. CPID, LIH, and SPA components are significantly showed differences in sexual dysmorphism in both male and female sexes. The regression formula for sex determination in adults using 3D-CT pelvic measurements in RSUD Dr. Soetomo Indonesia provides a pelvic model sex determination using CPID, LIH, and SPA values with higher validity and sensitivity for male identification, as well as higher a specificity for female identification.

\section{List Of Abbreviations}

ABS : Anterior breadth of the sacrum

AHS : Anterior height of sacrum

APOD : Anteroposterior pelvic outlet diameter

CPID : Conjugate pelvic inlet diameter

3D-CT : 3 Dimentional- computed tomography

LIB : Left iliac breadth

LIL : Left ischium length 
LIPI : Left ischial pubic index

LPL : Left pubic length

LGSN : Left width of greater sciatic notch

LIH : Left innominate height

MSCT : Multislice computed tomography

PSL : Pubic symphysis length

RIL : Right ischium length

RPL : Right pubis length

RGSN : Right width of greater sciatic notch

RIB : Right iliac breadth

RIH : Right innominate height

SPA : Sub pubic angle

TDSS : Transverse diameter of sacral segment 1

TPI : Transverse pelvic inlet

TPO : Transverse pelvic outlet

\section{Declarations}

\section{Ethical Clearance}

This manuscript has been accepted by ethical clearance department Dr. Soetomo Hospital. Ethical clearance number is 0106/LOE/301.4.2/VIII/2020.

\section{Funding}

This study did not receive any specific grant from funding / sponsorship agencies in the public, commercial, or not-for-profit sectors.

\section{Competing interests}

Rosy Setiawati has no conflict of interest in this study

Ika Ruriana has no conflict of interest in this study 
Prijambodo has no conflict of interest in this study

Giuseppe Guglielmi has no conflict of interest in this study

\section{Availability of data and materials}

All data generated or analysed during this study are included in this published article

\section{Author Contribution}

RS : Study conception and design; Analysis and interpretation of data; Drafting of manuscript; Critical revision

IR : Analysis and interpretation of data; Drafting of manuscript; Critical revision

$\mathrm{P}$ : Study conception and design; analysis and interpretation of data

GG : Study conception and design; Analysis and interpretation of data; Critical revision

\section{Acknowledgment}

A sincere gratitude to all my colleagues, family, and all the patients included in this study.

\section{References}

1. Franklin, D., Cardini, A., Flavel, A. and Marks, M. K. (2014) 'Morphometric analysis of pelvic sexual dimorphism in a contemporary Western Australian population', International Journal of Legal Medicine, 128(5), pp. 861-872. doi: 10.1007/s00414-014-0999-8.

2. Grivas, C. R. and Komar, D. A. (2008) 'Kumho, Daubert, and the nature of scientific inquiry: Implications for forensic anthropology', Journal of Forensic Sciences, 53(4), pp. 771-776. doi: 10.1111/j.1556-4029.2008.00771.x.

3. Decker, S. J., Davy-Jow, S. L., Ford, J. M. and Hilbelink, D. R. (2011) 'Virtual Determination of Sex: Metric and Nonmetric Traits of the Adult Pelvis from 3D Computed Tomography Models', Journal of Forensic Sciences, 56(5), pp. 1107-1114. doi: 10.1111/j.1556-4029.2011.01803.x.

4. Zech, W. D., Hatch, G., Siegenthaler, L., Thali, M. J. and Lösch, S. (2012) 'Sex determination from os sacrum by postmortem CT', Forensic Science International, 221(1-3), pp. 39-43. doi: 10.1016/j.forsciint.2012.03.022.

5. Krishan, K., Chatterjee, P. M., Kanchan, T., Kaur, S., Baryah, N. and Singh, R. K. (2016) 'A review of sex estimation techniques during examination of skeletal remains in forensic anthropology casework', Forensic Science International. Elsevier Ireland Ltd, 261, pp. 165.e1-165.e8. doi: 10.1016/j.forsciint.2016.02.007.

6. Mahfouz, M., Badawi, A., Merkl, B., Fatah, E. E. A., Pritchard, E., Kesler, K., et al. (2007) 'Patella sex determination by 3D statistical shape models and nonlinear classifiers', Forensic Science 
International, 173(2-3), pp. 161-170. doi: 10.1016/j.forsciint.2007.02.024.

7. Kolesova, O., Kolesovs, A. and Vetra, J. (2017) 'Age-related trends of lesser pelvic architecture in females and males: a computed tomography pelvimetry study', Anatomy \& Cell Biology, 50(4), p. 265. doi: 10.5115/acb.2017.50.4.265.

8. Amonoo-Kuofi, U. S. (1992) 'Changes in the Lumbosacral Angle, Sacral Inclination and the Curvature of the Lumbar Spine during Aging', Cells Tissues Organs, 145(4), pp. 373-377. doi:

$10.1159 / 000147392$.

9. Patriquin, M. L., Steyn, M. and Loth, S. R. (2005) 'Metric analysis of sex differences in South African black and white pelves', Forensic Science International, 147(2-3), pp. 119-127. doi:

10.1016/j.forsciint.2004.09.074.

10. Abdel Moneim, W. M., Abdel Hady, R. H., Abdel Maaboud, R. M., Fathy, H. M. and Hamed, A. M. (2008) 'Identification of Sex Depending on Radiological Examination of Foot and Patella', The American Journal of Forensic Medicine and Pathology, 29(2), pp. 136-140. doi:

10.1097/PAF.0b013e318173f048.

11. Mostafa, E. M. A., M. Dessouki, S. K., Hashish, R. K., M. Gad, A. A. and M. Khafagy, A. A. (2016) 'Adult Sex Identification Using Three-Dimensional Computed Tomography (3D-CT) of the Pelvis: A Study Among a Sample of the Egyptian Population', Arab Journal of Forensic Sciences and Forensic Medicine. doi: 10.12816/0026460.

12. Kolesova, O. and Vētra, J. (2012) 'Sexual dimorphism of pelvic morphology variation in live humans', Papers on Anthropology, 20, p. 209. doi: 10.12697/poa.2011.20.21.

13. Jordaan, H. V (1976) 'The differential development of the hominid pelvis.', South African medical journal = Suid-Afrikaanse tydskrif vir geneeskunde, 50(19), pp. 744-8. Available at: http://www.ncbi.nlm.nih.gov/pubmed/818723.

14. Leong, A. (2006) 'Sexual dimorphism of the pelvic architecture: a struggling response to destructive and parsimonious forces by natural \& mate selection.', McGill journal of medicine: MJM: an international forum for the advancement of medical sciences by students, 9(1), pp. 61-6. Available at: http://www.ncbi.nlm.nih.gov/pubmed/19529812.

15. Đurić, M., Rakočević, Z. and Đonić, D. (2005) 'The reliability of sex determination of skeletons from forensic context in the Balkans', Forensic Science International, 147(2-3), pp. 159-164. doi: 10.1016/j.forsciint.2004.09.111.

16. Igbigbi, P. and Msamati, B. (2009) 'Sex determination from femoral head diameters in black Malawians', East African Medical Journal, 77(3). doi: 10.4314/eamj.v77i3.46611.

17. Mostafa, E., Gad, A., Dessouki, S., Hashish, R. and Khafagy, A. (2017) 'Sex Determination Using Three-Dimensional Computed Tomography of Pelvis Measurements in Adult Egyptian population..', European Journal of Forensic Sciences, 4(2), p. 1. doi: 10.5455/ejfs.231267.

18. Klales, A. R., Ousley, S. D. and Vollner, J. M. (2012) 'A revised method of sexing the human innominate using Phenice's nonmetric traits and statistical methods', American Journal of Physical Anthropology, 149(1), pp. 104-114. doi: 10.1002/ajpa.22102. 
19. Ruriana I, Setiawati R, Prijambodo. (2020) 'Sex Identification Using Adult Pelvic 3D CT Scan: An Anthropometric Study.' International Journal of Research Publications, 64(1), pp. 1-9. doi: 1006411120201537.

\section{Figures}

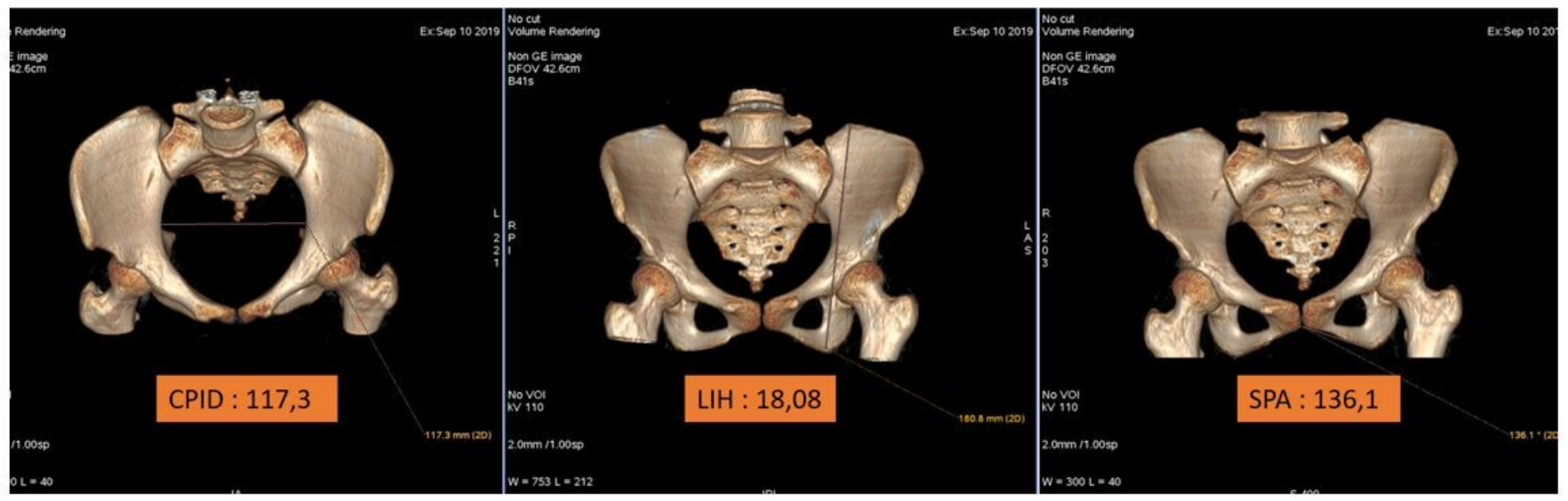

\section{Figure 1}

A case illustration of a 43 year-old woman with CPID, LIH, SPA values obtained from 3D images of the pelvis reconstructed from CT scan imaging system. From these parameter, the logistic regression formula is applied, resulting in the value of 30,9 (value $>0$ ) with the predicted sex is female. CPID : conjugate pelvic inlet diameter; LIH: left innominate height; SPA: sub pubic angle. 